\title{
Parents' experiences of caring for sons and daughters with schizophrenia: a qualitative analysis of coping
}

\author{
Benjamin Knudson \\ Springfield University Hospital \\ Adrian Coyle \\ University of Surrey
}

Correspondence to: Dr Benjamin Knudson, Department of Psychology, Springfield University Hospital, 61 Glenburnie Road, London SW17 7DJ Tel. 0208692 6249/50.

Email: knudsonben@hotmail.com

The full reference for the published version of this article is:

Knudson, B., \& Coyle, A. (2002). Parents’ experiences of caring for sons and daughters with schizophrenia: a qualitative analysis of coping. European Journal of Psychotherapy, Counselling \& Health, 5(2), 169-183. 


\title{
Parents' experiences of caring for sons and daughters with schizophrenia: a qualitative analysis of coping
}

\begin{abstract}
This study used a coping framework (Lazarus \& Folkman, 1984) to explore experiences of caring for a son or daughter with schizophrenia. Eight parents of people with schizophrenia were interviewed about their experiences and the transcripts of these interviews were subjected to thematic content analysis. The analysis indicated that negative symptoms represented the most burdensome stressor for parents and that coping strategies shifted from problem-focused to more emotionfocused forms (such as acceptance). In relation to the resources which were available to parents, the results indicated that support from social networks and mental health services was generally perceived to have been lacking. However, both informational and emotional support were available from self-help groups for relatives/carers. The implications of this study for therapeutic practice are discussed.
\end{abstract}

Keywords: schizophrenia; carers; coping; social support 


\section{Parents' experiences of caring for sons and daughters with schizophrenia: a qualitative analysis of coping}

\section{Introduction}

Current social policy objectives of community care in the UK have resulted in many relatives adopting the role of primary carer for individuals diagnosed with schizophrenia. Research findings indicate that up to $60 \%$ of individuals with schizophrenia continue to live with their relatives, mostly with parents (Kuipers, 1993). However, it is acknowledged that caring for a son or daughter with a mental 'illness' involves unique financial, social and emotional burdens (Doll, 1976; Gibbons et al., 1984; Potasznik and Nelson, 1984; Crotty and Krulys, 1986; Gubman and Tessler, 1987; Hatfield and Lefley, 1987; Maurin and Boyd, 1990; Oldridge and Hughs, 1992; Winefield and Harvey, 1993), due mainly to the changes in behaviour associated with clinical symptoms - that parents experience in their son or daughter (Birchwood and Smith, 1987). Within traditional understandings of schizophrenia, the clinical manifestations of the ‘condition' are commonly divided into positive and negative symptoms (Lemma, 1996). Positive symptoms are the florid manifestations of the condition (such as hallucinations, delusions and thought disorder) which are characteristic of psychotic episodes, while negative or residual symptoms refer to deficits in functioning, such as social isolation or withdrawal, marked impairment of role functioning and self-care and flat or inappropriate affect. The negative symptoms are more persistent across time, do not respond well to medication and consequently can be more demanding for carers. 
Given the substantial number of parents providing care in the community within such potentially challenging circumstances, it is important to understand their experiences and to examine the factors which contribute to the process of coping with the demands of caring for a son or daughter with schizophrenia. The aim of this study was to investigate the experiences of a group of parents in detail and specifically to identify aspects of caring for a son or daughter with schizophrenia that had been particularly difficult to cope with, coping strategies that had been used by parents to deal with the stresses of their caring role and resources that had been helpful in facilitating coping. These questions arise from the study's theoretical framework, which was provided by Lazarus and Folkman's (1984) interactional theory of stress and coping. According to this theory, the key aspects of adjustment to a stressful event are the nature of the stressor, the strategies adopted by the individual to cope with the stressor and the resources available to facilitate coping.

\section{Method}

Participants were recruited from two carers’ support groups organised by the National Schizophrenia Fellowship in south east England. Due to the study’s commitment to undertake a detailed exploration of individual accounts, the sample size was relatively small, consisting of eight parents (six mothers and two fathers) of people with schizophrenia. Their mean age was 61 years (range: 54-73 years); all were British, white and married. Each parent had one adult child with schizophrenia; five parents had a son with schizophrenia and three had a daughter. These offspring had a mean age of 34 years (range 25-44 years) and had had a diagnosis of schizophrenia for a 
mean duration of 13 years (range 5-25 years). At the time of the interview, five were living with their parents, two were living in independent accommodation and one was currently in a psychiatric hospital. Those parents whose children who were not currently living with them nevertheless saw themselves as (having been) significantly involved in the care of the children following the diagnosis of schizophrenia.

Each participant was interviewed using a semi-structured interview format. Interviews covered their offspring's psychiatric history and current symptoms (which are not reported in this article), the nature of the parents' care-giving role (including any difficulties), their methods of coping and resources available to and used by them. Interviews were audio-taped and the tapes were transcribed verbatim. Transcripts were subjected to a form of thematic content analysis (Smith, 1995; Pauli and Bray, 1998), which involved reading and re-reading the transcripts to discern themes (commonalities of reported experience). Where appropriate, these were then assigned to theoretical categories derived from Lazarus and Folkman’s (1984) interactional theory of stress and coping - the stressors which parents reported, their coping strategies and coping resources. The aim of this stage of analysis was to develop a theoretically enriched understanding of the experiences reported by participants. By starting with themes derived from participants' accounts, this two stage process avoids the risk of entirely overwriting participants' subjectivities with $a$ priori categories. In the analysis presented here, interpretations are illustrated by data extracts to enable readers to assess their persuasiveness (Elliott et al., 1999). In the quotations, empty square brackets indicate where material has been omitted, material 
within square brackets is provided for clarification and ellipsis points (...) indicate a pause in the flow of participants' speech. Any information that might compromise participants' confidentiality - including their names and the names of their children has been changed.

\section{Results}

The analysis will begin by examining how parents reported having coped with the stressors associated with their caring role. The main stressors identified by the parents centred on the common clinical symptoms associated with schizophrenia; the coping strategies described in the interviews will be discussed in relation to these symptoms. Consideration will then be given to the coping resources that parents identified as having been available to them.

\section{Clinical symptoms and coping strategies}

Positive symptoms: While all the parents had had to cope with the positive symptoms associated with their offspring's schizophrenia, for most participants these were not of immediate concern at the time of the interview as hallucinations and delusions had mostly subsided. In those cases where delusions were an ongoing feature of their son's or daughter's condition, various coping methods were described. Some parents attempted to negotiate rational explanations for delusional beliefs with their son or daughter. For example, Lisa's son had delusions about telepathy. When asked how she responded to these ideas, she said, 'It depends what the idea is. But, you know, [if 
he says] "I knew you were going to say that”, you know, I’d say "Well, it could be you know me very well or that could just be coincidence”.

However, most participants found this strategy to be ineffective as their offspring's delusional beliefs were not open to refutation and required very little in the way of evidence to support them. Over time, these carers reported having learned to adopt a strategy of 'constructive disengagement' (Birchwood and Smith, 1987), wherein they avoided actively challenging or colluding with the delusion by refusing to enter into any lengthy discussion about it. For example, Vivienne said: 'I won’t discuss it with him any more, no, because I know we get nowhere. At one time I used to think “Oh, if only he'd talk and we could get to the bottom of this” but it doesn't get to anywhere - it doesn't get anywhere, no'. For most participants, this strategy seemed to have evolved following a frustrating period during which they went to great lengths to challenge their son's or daughter's delusional beliefs (which implies that those parents who were currently engaged in this process might ultimately also turn to a strategy of disengagement). In the absence of any guidance on how to cope with the symptoms, carers reported having gone through an arduous process of trial and error in developing effective coping strategies and many bemoaned the lack of professional advice during this difficult period.

Negative symptoms: While the positive symptoms of their offspring's condition contributed to the burden experienced by the parents in this study, the negative symptoms or behavioural deficits associated with schizophrenia proved more 
troublesome - a finding which is consistent with surveys of family burden (Creer and Wing, 1974; Fadden et al., 1987). Many commentators have suggested that negative symptoms are particularly problematic because of the difficulty carers have in attributing these to 'mental illness' (Fadden et al., 1987; Hooley et al., 1987; Barrowclough and Tarrier, 1992). Negative symptoms involve an absence of normal functions which the person was once able to perform, so they are easily attributed to an unwillingness on the part of the person diagnosed with schizophrenia to engage in appropriate behaviours, rather than being seen as the symptoms of a 'genuine illness'.

However, there was little evidence of this attributional process in the present study. All participants demonstrated a sound understanding of the traditional symptomatology of schizophrenia and attributed their son's or daughter's negative symptoms to the effects of mental illness rather than to person-related factors. Instead, the major difficulty which carers experienced in relation to negative symptoms appeared to arise from their offspring's increased dependence on them. For example, Karen explained how her son’s social withdrawal meant that he relied exclusively on her and her husband for social contact and could sometimes act in quite manipulative ways in order to increase his contact with them: 'There are times when he says “Mum, I just can’t go out today. I don’t want to go down to the shops they're talking about me in the shop”, you know, "Call in and get me some tobacco on the way because I don't want to go to the shop” [ ]. But he can be quite manipulative because he's told me that he will say that people are talking about him 
even when he knows that they're not [ ] because he’s lonely and he wants company and he hasn't got anyone else'.

Participants reported using various strategies to cope with their offspring's social withdrawal or lack of motivation. In their review of coping literature, Stroebe and Stroebe (1995) noted that most studies distinguish between two main types of coping response: problem-focused strategies, which are directed towards altering the source of stress, and emotion-focused strategies, which attempt to manage or reduce the emotional distress associated with the stressful situation. Faced with their offspring's social withdrawal or lack of motivation, some parents reported having tried actively to engage their son or daughter in family activities and/or having encouraged them to pursue hobbies and personal interests - an example of problem-focused coping. George illustrated this type of coping response:

George: I spent a lot of time trying to find something which he would be interested in, you know... I bought him a camera, you know - 'Why don’t you learn to be a photographer?' - and pointed him in that direction [ ]. Interviewer: So your response to this was to try and bring him out of himself and engage him in certain activities. How effective was that? George: Not very, no. [ ] We got more and more disappointed that we could not succeed in doing that.

Sonia also described her attempts to encourage her daughter to be more outgoing, which were met with limited success: 
Sonia: We try every now and then and say 'Couldn’t you see so-and-so or somebody?’ or whatever. Um...and it doesn’t usually work, you know. Interviewer: So how do you cope with it when she is being quite withdrawn? Sonia: Well, if you're referring to the last three months, I probably leave her alone because I don't really - I can't alter the fact, you know, and I - I've learned to live with it [ ]. When she’s withdrawn I just leave her to it these days.

Again, a process of trial and error seemed to have occurred for most participants, with a gradual acceptance of their offspring's withdrawal or lethargy and a consequent reduction in their own efforts to motivate them. This illustrates a gradual shift from problem-focused strategies to more emotion-focused forms of coping, such as acceptance.

The importance of acceptance was emphasised by many parents, as this form of coping had clear benefits for their own well-being. As Lisa explained, accepting her son's withdrawal helped to reduce her own anxiety about his behaviour:

Interviewer: Did his withdrawal affect you differently in the past? Lisa: Yes, it did cos, you know, I had in my mind 'What is he doing that for?' all the time instead of just letting it be. So that caused a conflict for me - my own thought on that one...'What is he doing that for?'. It's just to let him be 
[ ] and that seems to have helped in a way - total acceptance [ ]. It's helped me feel better about it - now I don’t worry so much.

In addition, some parents indicated that acceptance had also had a beneficial effect on their offspring. Lisa observed that, in relation to her son, 'It's helped him as well as me. Me controlling my problem of wondering "What's he thinking?" and all this sort of thing [laughs] has helped Martin as well [ ] because I found out as I went along that the pressure wasn't a good thing. So you'd just have to let things come out naturally’.

However, the development of a position of acceptance and of recognition that there is little that the parent can actually do to improve their offspring's condition may be a long and difficult process, compounded by a sense of helplessness. The process of arriving at a position of acceptance seemed to have been facilitated for some parents by a greater understanding of the reasons for their offspring's withdrawal. Lisa commented: 'Now his withdrawal doesn't affect me because when he withdraws now I know sometimes that it is because he's getting a bad voice. But he's dealing with it and that's the main point'.

For others, acceptance of their relative's behaviour seemed to have developed through a process of downward social comparison. For example, Sonia said, ‘Um...but then, you know, if you can find someone who’s worse off than you and your, uh, what she's doing now is a lot better than some of them. Um, you have to 
look for chinks of light in your own...however small they might be'. This contradicts a central tenet of social comparison theory (Festinger, 1954) which states that people will choose others who are doing slightly better than themselves for comparison purposes in order to learn how to cope more effectively. However, a similar process of downward social comparison has been observed in people with cancer (Taylor, 1983; Wood et al., 1985) and there is a body of evidence reviewed by Wills (1981, 1987) which suggests that, under threat, individuals tend to make downward social comparisons in order to bolster self-esteem (although other writers suggest that the process is more subtle and complex: see Taylor and Lobel, 1989; Aspinwall and Taylor, 1993). For the parents in this study, such comparisons seemed to have been made in order to accept what they could not change. Where problem-focused strategies had failed to improve their offspring's behaviour, parents reported that they gradually began to focus on managing their own emotional reactions to the situation. Comparing their son or daughter to others who were functioning at a lower level or developing a better understanding of the reasons behind their offspring's withdrawal seemed to have helped parents move towards acceptance and improved their emotional well-being in the face of an ongoing (and difficult-to-change) stressful situation.

\section{Resources available to carers}

According to the interactional theory of stress and coping (Lazarus and Folkman, 1984), the resources available to an individual play a major role in determining that person's ability to cope with a stressful event or situation (coupled with the person's 
ability to access and make productive use of these resources) . Parents' resources will be considered under the headings of social support, self-help groups and mental health services.

Social support: Although many studies have suggested that families in which someone has schizophrenia experience social isolation (Anderson et al., 1984; Namyslowska, 1986; McCreadie et al., 1987), the parents in this study had experienced a range of responses from their family and friends. Some felt well supported by their social network; this seemed to be related to their family or friends having had first-hand experience of mental distress themselves. However, others did not feel that social support was forthcoming. Some parents spoke of their reluctance to seek support: 'I think probably we ourselves perhaps withdrew or - or were - felt, um, a bit inhibited in making social contact with other people because we felt they wouldn’t understand or we didn’t feel we wanted to bring that kind of thing into social contact, you know - you don't want people to identify your family with' (Sonia). Most participants referred to the perceived stigma of mental illness and it appeared that this was a key factor underlying the social isolation experienced by some parents.

Self-help groups: All participants were members of the National Schizophrenia Fellowship and attended relatives'/carers' groups. Their comments indicated that they derived many benefits from these groups, principally the opportunity to meet others who truly understood their situation, which was said to have alleviated their sense of 
isolation. For example, Karen said, 'I’ve found that people that have not experienced mental illness - severe mental illness - haven’t got a clue...unless you’ve experienced it, you've no idea...um... and the best people to talk to as far as, um, feeling included and feeling that you're understood, is to other carers'.

Belonging to a relatives'/carers' group, then, helped to meet support needs which were frequently not met elsewhere. Another benefit mentioned by parents was the sharing of information. The provision of basic information about the 'nature' and 'course' of schizophrenia has been consistently rated as meeting one of the most important needs of relatives (Birchwood and Smith, 1987; Perring et al., 1990; Heron, 1998). Among the participants in this study, relatives'/carers' groups were evaluated as providing an ideal context for the provision of such information to challenge ‘social myths’ about schizophrenia. For example, George said, ‘The prime value [of the relatives' group] is when you don't understand what you're...at the start of the illness when you are quite unfamiliar with mental illness at all, you've never experienced it, it's not been talked about, uh, it's not generally known - you have all these scares about violence and murderous intent and suicide and all the rest of it, which is all you hear during the normal course of events. [ ] So information and practical advice is the main advantage'.

The social support literature has distinguished between emotional support, which conveys to the person that they are accepted and understood, and informational support, consisting of advice and guidance on how to deal with problem situations 
(Cohen and Wills, 1985). From the parents' comments, it seemed that both types of support appeared to have been provided in their relatives'/carers' groups. However, while the value of self-help groups for relatives of people diagnosed with schizophrenia is being increasingly recognised (Hatfield and Lefley, 1987; Heller et al., 1997), some participants spoke of having experienced difficulties when attending such groups. For example, Elizabeth described how attending a relatives’ group proved overwhelming for her when her son first developed schizophrenia: ‘It wasn’t for a couple of years before I was desensitised so that I could talk to people without experiencing the pain - uh - emotional pain, I suppose at the thought of it [ ]. I found it very difficult, even going to the support group, because every time I was to talk about it or open my mouth about it, I'd experience the pain. So in the initial stages, if you like, when you need support, um, it was too much to take'. Joan also talked of how attending such groups may prove dispiriting for parents whose children have recently been diagnosed and how it might deprive them of hope for the future: 'One difficulty is [ ] that the nucleus of this group that I run - we're all getting quite old and our children have been ill for quite a long time [ ] so if you get someone new coming along in a crisis it’s very difficult and you can comfort them and say “Things get better with time” and so on but when they look at us and they can see that we're still caring after twenty-five years, it’s not very encouraging’

Mental health services: Although mental health services may potentially act as a significant coping resource for parents, a high level of dissatisfaction with these services was reported by participants in this study, which is consistent with other 
studies (Spaniol et al., 1987; Perring et al.,1990). The main reasons for this dissatisfaction were identified as a lack of information about the nature, course and behavioural management of schizophrenia and a sense of being excluded from the treatment process.

All participants again emphasised the importance of obtaining comprehensive, accurate information about schizophrenia, particularly in the early stages. Drawing upon their experiences, they felt - with the exception of one participant - that this had not been adequately provided by the mental health services with which they had been in contact. Joan's experience, for example, was shared by many:

Joan: Nobody ever tells you anything, and I think in the early stages you need a lot of support and you need a lot of information and explanation and so on []. Interviewer: Specifically, what kind of information do you think you needed at that point?

Joan: Well, I needed information about the course of the illness, the medicines, the symptoms. Because this is like, you know, it hit me, and people don't know anything about schizophrenia and they think it's a dual personality, don't they?

Participants described the onset of schizophrenia in a son or daughter as a bewildering and often frightening experience. This was compounded by the fact that, 
as Joan indicated, their knowledge about the condition was often limited or misinformed by social myths. However, as one parent observed, eliciting appropriate information from professionals was 'like drawing blood from a stone’ (Karen).

The second major complaint made by many parents concerned the failure of the mental health system to include them in the treatment process. For example, Sonia expressed her feeling of exclusion: 'We ourselves, really, have been largely sidelined [ ]. Uh, things were said "Well, these are now confidential matters" and, um, we still find that very difficult because, uh, how can you be not informed about somebody that you're caring for? Um... and you need to know certain things - otherwise you can't care properly for that person'.

These comments indicate that parents wished for greater co-operation with mental health staff. Professionals' reluctance to include relatives in the treatment process was attributed to overly strict interpretations of confidentiality, which were felt to be inappropriate. Many parents also felt they would have benefited from psychological help and support from mental health professionals. This was rarely offered but those who had experienced counselling had found it beneficial.

\section{Discussion}

This research has provided some insights into the nature of the stresses that parents may face in caring for a son or daughter who has been diagnosed with schizophrenia. The sample chosen for this study was very specific and the results need to be 
interpreted in the light of this. All participants belonged to self-help groups and had been caring for their son or daughter for some years. This means that only these particular perspectives on caring for a child with schizophrenia were represented in this study. For example, the fact that negative symptoms associated with schizophrenia constituted the parents’ primary burden may be related to the length of time for which they had been caring for their son or daughter. This suggestion is consistent with the results of a study which found that the type of burden experienced by parents shifted from a concern with the management of challenging behaviour during the early stages of the condition to an increased preoccupation with issues of emotional involvement arising from the effect of negative symptoms in later stages (Cook et al., 1994). Also, the data relating to the benefits of self-help groups need to be interpreted in the light of the fact that all participants were attending such groups and so it is reasonable to assume that they had derived some benefits from this. Had the research recruited parents who did not belong to a relatives'/carers' group or who had ceased attending, the results may have been quite different. Future research needs to recruit those who are unable - for whatever reason - to benefit from such groups and to explore alternative coping resources that might be used by these parents.

A further limitation is that all participants were recruited from a specific geographical location. However, the results of other studies (for example, Perring et al., 1990; Lamb and Layzell, 1995) suggest that relatives’ sense of exclusion from the treatment process and their difficulties in eliciting information from professionals may be common experiences which are not restricted to particular geographical areas. The 
ethnic homogeneity of the sample does represent a limitation, though: further research is needed to explore the experiences of parents from different ethnic communities as it is reasonable to assume that their experiences may be different because of group-specific social representations of schizophrenia and because of different histories of involvement with mental health services across ethnic communities (Fernando, 1988, 1995; Pilgrim and Rogers, 1999).

Despite this, if the present study has succeeded in accessing some common parental experiences, the implications for therapeutic practice would be considerable. Mental health professionals need to recognise the difficulties experienced by parents who are performing a caring role for sons and daughters who have been diagnosed with schizophrenia and to offer appropriate assistance and support to promote effective coping. It has been recommended that practitioners adopt a needs-led approach (Birchwood and Smith, 1987; Barrowclough and Tarrier, 1992), in which the diverse needs of families are recognised and individually-tailored interventions are designed to meet these needs. However, the findings from this study suggest that, in the early stages of schizophrenia, there may be a common desire among parents for clear, comprehensive information about schizophrenia, the role of medication and possibly other matters too (such as the management of challenging behaviours). This may create dilemmas for mental health professionals whose practice is informed by the now substantial literature which adopts a critical and deconstructive stance towards schizophrenia (for example, Bentall, 1990; Boyle, 1990, 1996; Parker et al., 1995). We have not invoked this literature in this article because we wished to frame our 
analysis in terms of the phenomenology of the parents, whose conceptualisations of schizophrenia were firmly located within a traditional medical model. Instead of meeting parents' informational needs within the parameters of this model, some mental health professionals may wish to challenge this conceptualisation and introduce parents to alternative and perhaps more useful discourses within which to interpret their offspring's condition.

For parents who have been dealing with their offspring's schizophrenia for some time, the mental health professional's role may be to facilitate the development of more emotion-focused strategies and to help parents come to terms with and accept the persistent symptoms associated with their offspring's condition. This might involve working with parents to acknowledge the limits of their ability to change certain aspects of their son's or daughter's condition, thereby allowing them to focus on their own emotional well-being. The provision of a non-judgmental environment where feelings such as anger, grief, hopelessness and guilt can be expressed and worked through might be an important part of this therapeutic process. The potential value of mental health professionals facilitating a parental shift towards greater acceptance has been indicated by research on expressed emotion, which has demonstrated that individuals said to be suffering from schizophrenia are highly sensitive to environmental stress (for example, Brown et al., 1958, 1972; Brown, 1959; Leff and Vaughn, 1985; Parker and Hadzi-Pavlovic, 1990; Bebbington and Kuipers, 1994; Butzlaff and Hooley, 1998). Some carers find that reducing pressure on their relatives with a diagnosis of schizophrenia and developing a position of 
acceptance can help to alleviate such stress and thus can have a beneficial effect. Protective family environments have been shown to be characterised by a non-critical and somewhat detached attitude on the part of carers (Leff and Vaughn, 1985), an attitude which is more likely to be fostered by emotion-focused strategies, such as acceptance and distancing, than problem-focused strategies which aim to change the behaviour of the relative. The promotion of this type of coping response, then, may serve the dual purpose of improving parents’ psychological well-being and protecting offspring from any undue pressure or stress. However, further research is required to allow recommendations for therapeutic practice to be advanced with greater confidence.

\section{References}

Anderson, C., Hogarty, G., Bayer, T. and Needleman, R.A. (1984) 'Expressed emotion and social networks of parents of schizophrenic patients', British Journal of Psychiatry, 144: 247-55.

Aspinwall, L.G. and Taylor, S.E. (1993) ‘Effects of social comparison direction, threat and self-esteem on affect, self-evaluation, and expected success’, Journal of Personality and Social Psychology, 64: 708-22.

Barrowclough, C. and Tarrier, N. (1992) Families of Schizophrenic Patients: Cognitive Behavioural Intervention, London: Chapman and Hall.

Bebbington, P. and Kuipers, L. (1994) 'The predictive utility of expressed emotion in schizophrenia: an aggregate analysis’, Psychological Medicine, 24: 707-18.

Bentall, R.P. (1990) (ed.) Reconstructing Schizophrenia, London: Routledge. 
Birchwood, M. and Smith, J. (1987) 'Schizophrenia and the family’, in J. Orford (ed.) Coping with Disorder in the Family, London: Croom Helm.

Boyle, M. (1990) Schizophrenia: A Scientific Delusion? London: Routledge Boyle, M. (1996) 'Schizophrenia: the fallacy of diagnosis', Changes: An International Journal of Psychology and Psychotherapy, 14: 5-13.

Brown, G.W. (1959) ‘Experiences of discharged chronic schizophrenic mental hospital patients in various types of living group', Millbank Memorial Fund Quarterly, 37, 101-31.

Brown, G.W., Birley, J.L.T. and Wing, J.K. (1972) 'Influence of family life on the course of schizophrenic disorders: a replication', British Journal of Psychiatry, 121: 241-58.

Brown, G.W., Carstairs, G.M. and Topping, G.G. (1958) 'Post hospital adjustment of chronic mental patients', Lancet, 2: 685-9.

Butzlaff, R. and Hooley, J. (1998) 'Expressed emotion and psychiatric relapse: a meta-analysis’, Archives of General Psychiatry, 55: 547-52.

Cohen, S. and Wills, T.A. (1985) 'Stress, social support and the buffering hypothesis’, Psychological Bulletin, 98: 310-57.

Cook, J., Lefley, H., Pickett, S. and Cohler, B. (1994) ‘Age and family burden among parents of offspring with severe mental illness', American Journal of Orthopsychiatry, 64: 435-47.

Creer, C. and Wing, J.K. (1974) Schizophrenia at Home, Surbiton: National Schizophrenia Fellowship. 
Crotty, P. and Krulys, R. (1986) 'Are schizophrenics a burden to their families? Significant others' views', Health and Social Work, 11: 173-88.

Doll, W. (1976) 'Family coping with the mentally ill: an unanticipated problem of deinstitutionalization', Hospital and Community Psychiatry, 27: 182-5.

Elliott, R., Fischer, C.T. and Rennie, D.L. (1999) 'Evolving guidelines for publication of qualitative research studies in psychology and related fields', British Journal of Clinical Psychology, 38: 215-29.

Fadden, G., Bebbington, P. and Kuipers, L. (1987) 'The burden of care: the impact of functional psychiatric illness on the patient's family', British Journal of Psychiatry, 150: 285-92.

Fernando, S. (1988) Race and Culture in Psychiatry, London: Croom Helm.

Fernando, S. (1995) (ed.) Mental Health in a Multi-Ethnic Society: A MultiDisciplinary Handbook, London: Routledge.

Festinger, L.A. (1954) ‘A theory of social comparison processes’, Human Relations, 7: 117-40.

Gibbons, J.S., Horn, S.H., Powell, J.M. and Gibbons, J.L. (1984) 'Schizophrenic patients and their families: a survey in a psychiatric service based on a DGH unit', British Journal of Psychiatry, 144: 70-7.

Gubman, G. and Tessler, R. (1987) 'The impact of mental illness on families’, Journal of Family Issues, 8: 226-45.

Hatfield, A.B. and Lefley, H.P. (1987) (eds) Families of the Mentally Ill: Coping and Adaptation, New York: Guilford Press. 
Heller, T., Roccoforte, J.A., Hsieh, K., Cook, J.A. and Pickett, S.A. (1997) 'Benefits of support groups for families of adults with severe mental illness', American Journal of Orthopsychiatry, 67: 187-98.

Heron, C. (1998) Working with Carers, London: Jessica Kingsley Publishers.

Hooley, J.M., Richters, J.E., Weintraub, S. and Neale, J.M. (1987) ‘Psychopathology and marital distress: the positive side of positive symptoms', Journal of Abnormal Psychology, 96: 27-33.

Kuipers, L. (1993) 'Family burden in schizophrenia: implications for services’, Social Psychiatry and Psychiatric Epidemiology, 28: 207-10.

Lamb, B. and Layzell, S. (1995) Disabled in Britain: Behind Closed Doors - The Carer's Experience, London: Scope.

Lazarus, R.S. and Folkman, S. (1984) Stress, Appraisal, and Coping, New York: Springer Publishing Company.

Leff, J. and Vaughn, C. (1985) Expressed Emotion in Families: Its Significance for Mental Illness, New York: Guilford Press.

Lemma, A. (1996) Introduction to Psychopathology, London: Sage.

Maurin, J.B. and Boyd, C.B. (1990) 'Burden of mental illness on the family: a critical review’, Archives of Psychiatric Nursing, 4: 99-107.

McCreadie, R.G., Wiles, D.H., Moore, J.W. and Grant, S.M. (1987) 'The Scottish first episode schizophrenia study: IV. Psychiatric and social impact on relatives', British Journal of Psychiatry, 150: 340-4.

Namyslowska, I. (1986) 'Social and emotional adaptation of the families of schizophrenic patients’, Family Systems Medicine, 4: 398-407. 
Oldridge, M.L. and Hughs, I.C.T. (1992) 'Psychological well being in families with a member suffering from schizophrenia’, British Journal of Psychiatry, 161: 249-51.

Parker, G. and Hadzi-Pavlovic, D. (1990) ‘Expressed emotion as a predictor of schizophrenia relapse: an analysis of aggregated data’, Psychological Medicine, 20: 961-5.

Parker, I., Georgaca, E., Harper, D., McLaughlin, T. and Stowell-Smith, M. (1995) Deconstructing Psychopathology, London: Sage.

Pauli, R. and Bray, D. (1998) 'Content analysis of qualitative data', in P. Clarkson (ed.) Counselling Psychology: Integrating Theory, Research and Supervised Practice, London: Routledge.

Perring, C., Twigg, J. and Atkin, K. (1990) Families Caring for People Diagnosed as Mentally Ill: The Literature Re-examined, London: HMSO.

Pilgrim, D. and Rogers, A. (1999) (eds) A Sociology of Mental Health and Illness, $2^{\text {nd }}$ edn, Buckingham: Open University Press.

Potasznik, H. and Nelson, G. (1984) 'Stress and social support: the burden experienced by the family of a mentally ill person', American Journal of Community Psychology, 12: 589-607.

Smith, J.A. (1995) ‘Semi-structured interviewing and qualitative analysis’, in J.A. Smith, R. Harré and L. Van Langenhove (eds) Rethinking Methods in Psychology, London: Sage.

Spaniol, L., Jung, H., Zipple, A.M. and Fitzgerald, S. (1987) ‘Families as a resource in the rehabilitation of the severely psychiatrically disabled', in A.B. Hatfield 
and H.P. Lefley (eds) Families of the Mentally Ill: Coping and Adaptation, New York: Guilford Press.

Stroebe, W. and Stroebe, M.S. (1995) Social Psychology and Health, Buckingham: Open University Press.

Taylor, S.E. (1983) 'Adjustment to threatening life events: a theory of cognitive adaptation’, American Psychologist, 38: 1161-73.

Taylor, S.E. and Lobel, M. (1989) 'Social comparison activity under threat: downward evaluation and upward contacts’, Psychological Review, 96: 56975.

Wills, T.A. (1981) 'Downward comparison principles in social psychology’, Psychological Bulletin, 90: 245-71.

Wills, T.A. (1987) 'Downward comparison as a coping mechanism’, in C.R. Snyder and C.E. Ford (eds) Coping with Negative Life Events: Clinical and Social Psychological Perspectives, New York: Plenum Press.

Winefield, H.R. and Harvey, E.J. (1993) 'Determinants of psychological distress in relatives of people with chronic schizophrenia', Schizophrenia Bulletin, 19: 619-26.

Wood, J.V., Taylor, S.E. and Lichtman, R.R. (1985) 'Social comparison in adjustment to breast cancer', Journal of Personality and Social Psychology, 49: 1169-83. 